\title{
EMBRITTLING COMPONENTS IN SINTERED STEELS: COMPARISON OF PHOSPHORUS AND BORON
}

\author{
Herbert Danninger, Vassilka Vassileva*, Christian Gierl-Mayer
}

\begin{abstract}
In ferrous powder metallurgy, both boron and phosphorus have been known to be sintering activators for a long time. However, the use has been widely different: while $P$ is a standard additive to sintered iron and steels, boron has been frequently studied, but its use in practice is very limited. Both additives are also known to be potentially embrittling, though in a different way. In the present study the differences between the effects of both elements are shown: while $P$ activates sintering up to a certain threshold, in part by stabilizing ferrite, in part by forming a transient liquid phase, boron is the classical additive enhancing persistent liquid phase, being virtually insoluble in the iron matrix. The consequence is that sintered steels can tolerate quite a proportion of phosphorus, depending on composition and sintering process; boron however is strongly embrittling in particular in combination with carbon, which requires establishing a precisely defined content that enhances sintering but is not yet embrittling. The fracture mode of embrittled materials is also different: while with $\mathrm{Fe}-\mathrm{P}$ the classical intergranular fracture is observed, with boron a much more rugged fracture surface appears, indicating some failure through the eutectic interparticle network but mostly transgranular cleavage. If carbon is added, in both cases transgranular cleavage dominates even in the severely embrittled specimens, indicating that no more the grain boundaries and sintering necks are the weakest links in the systems.
\end{abstract}

Keywords: Sintered steel, phosphorus, boron, embrittlement

\section{INTRODUCTION}

For ferrous powder metallurgy products, in particular those manufactured through the press-and-sinter route, density - strictly speaking relative density - is the single most important property affecting all other ones, such as mechanical, electrical magnetic and thermal properties [1-3]. In addition to the density there is however also the geometry of the sintering contacts that determines the properties, in particular the mechanical ones [4]. Therefore, improving the property profile of a sintered steel can be done through various routes:

- imcreasing the total density through the compacting route (higher pressures, warm compaction, double pressing, high velocity compaction , ...) [5-7]

- Improving the local density where it is needed by mechanical densification, e.g. at the tooth flanks of gears [8].

\footnotetext{
Herbert Danninger, Vassilka Vassileva*, Christian Gierl-Mayer: Technische Universität Wien, Institut für Chemische Technologien und Analytik, A-1060 Wien/Vienna, Austria, *now: OMV AG, A-1020 Wien
} 
- Increasing the density through the sintering route. This is the usual way e.g. for hardmetals, in which case a persistent liquid phase results in virtually pore-free specimens. In MIM, the use of very fine powders, $<20 \mu \mathrm{m}$, results in high sintering activity and thus in densification by solid state sintering. In both cases, however, densification means shrinkage during sintering, with the risk to compromise the dimensional precision.

increasing the strength of the interparticle bridges during sintering. This way improves the mechanical strength while virtually retaining the dimensions of the specimens and thus also the precision. This can be done by increasing the sintering temperature and/or by using sintering activators that enhance material transport. Transient liquid phases can be very effective here [9].

For PM steel precision parts, the options offered by compacting techniques have been intensely used in the last decades and have contributed to the expansion of PM into new fields of application, esp. those where improved property profiles are required [10]. The use of the sintering approaches has been rather sluggish in comparison, in part because of dimensional concerns, in part because of cost problems. High temperature sintering is done to some extent for press-and-sinter parts, but its main field is still metal injection moulding. Sintering with transient liquid phase is extremely widespread in ferrous parts production since about half of all parts manufactured are based on $\mathrm{Fe}-\mathrm{Cu}-\mathrm{C}$, and the transient $\mathrm{Cu}$ melt formed helps retaining dimensional stability, through the well-known "copper swelling" effect [11].

Another additive that activates sintering is phosphorus. This element is regarded as extremely detrimental in ferrous ingot metallurgy, because of its pronounced tendency to segregate to the grain boundaries and cause extreme embrittlement. In powder metallurgy, in contrast, phosphorus is used to a considerable extent as sintering activator $[12,13]$, although it is known that care has to be taken to avoid embrittlement also here.

A further element that has been known for a long time to activate sintering is boron. Already in the mid-1950s it was shown that addition of small amounts of B to Fe powder compacts results in pronounced densification. However it was also recognized that densification easily comes along with pronounced embrittlement [14].

In the present study, both sintering activators are compared, and it is shown under which circumstances embrittlement occurs.and which are the underlying parameters.

\section{MECHANISMS OF SINTERING ACTIVATION AND DRAWBACKS}

Phosphorus and boron both activate sintering, though in very different ways. The simpler route is that of boron (e.g. $[15,16]]$. B is virtually insoluble in $\mathrm{Fe}$ (as in $\mathrm{Ni}$ and many other refractory metals [17]), and with $\mathrm{Fe}$ it forms a eutectic at $1177^{\circ} \mathrm{C}[17,18]$. If therefore a mix of iron (or stee $\overline{1}$ ) powder and a boron carrier - elemental boron, ferroboron or a boride - is heated above this temperature, the Fe-B eutectic melts and forms a liquid phase that is persistent since the liquid-forming additive boron is insoluble in the matrix. Boron therefore remains in the liquid phase which enhances all the processes known from liquid phase sintering, i.e. rearrangement, solution-reprecipitation etc. [19-21]. In the case of boron, the processes are further enhanced by the fact that this eutectic liquid is very mobile and wets the matrix surface well, i.e. it penetrates pore channels and pressing contacts rapidly. This results in fast densification, the porosity being dramatically reduced, and may finally result in almost dense components even if relatively coarse starting powders are used, which is rather uncommon in persistent liquid phase sintering.

The penalty for this welcome densification is of course marked shrinkage and the risk of distortion. The main problem is however the Fe-B liquid phase. Since boron is 
insoluble in solid Fe both at temperatures above the eutectic but even more so at lower temperatures, the eutectic melt solidifies during cooling but remains in place as boride eutectic. Such eutectic structures - regardless if carbidic or boridic - are known to be brittle, and this holds also for this case. Eutectic structures are however not critical as long as they are isolated. For gravity sintered filters it has been shown that even relative large amounts of boride eutectic do not do any harm as long as they are isolated, i.e. concentrated at the sintering necks [22]. As soon as however this boride eutectic forms a continuous network in the sintered body, severe embrittlement occurs. Therefore it is essential to establish the boron content in such a way that there is already activation - which requires a certain minimum content - while the B level has to kept sufficiently low to prevent formation of a continuous network.

At first this seems to be not too difficult but simply a question of admixing the right boron content. However, the situation is further complicated by the tendency of boron to react with the sintering atmosphere. During sintering in $\mathrm{N}_{2}$ containing atmospheres, boron rapidly forms hexagonal boron nitride which is very stable, boron thus being deactivated and unable to form a liquid phase, and the effect of the liquid phase activation is completely lost [23]. Sintering in $\mathrm{H}_{2}$, in contrast, retains the boride eutectic, but part of the boron reacts with $\mathrm{H}_{2}$ to form gaseous compounds, mainly $\mathrm{B}_{2} \mathrm{H}_{6}$ according to [24]. The effect is similar to decarburization by $\mathrm{H}_{2} \mathrm{O}$ in the atmosphere, and it results in lower $\mathrm{B}$ contents and thus lower densification at and near the surface of the compact. More shrinkage in the core than in the rim area however causes X-shape distortion, a very unwelcome effect. In general, this reactivity of B with the atmosphere further complicates the retaining of the optimum $\mathrm{B}$ content, even if it has been set in the original powder compact. The only truly reliable atmosphere for B is vacuum, but this is economically unattractive for ferrous PM parts. Ar would also be inert, but it inhibits densification since Ar is insoluble in the metallic matrix and if trapped in closed pores, the internal pressure prevents pore closing.

Phosphorus, in contrast, is a much more tolerant sintering activator, which is the reason why it has been used in the industry to a considerable degree. Phosphorus is reasonably well soluble in iron, the maximum solubility being 2.8 mass $\%$ at $1048^{\circ} \mathrm{C} \mathrm{[18]}$. This is the temperature of the Fe-P eutectic with 10.2 mass $\% \mathrm{P}$. The enormous temperature interval between the melting point of $\mathrm{Fe}$ and the eutectic temperature is the reason for the pronounced segregation tendency of $\mathrm{P}$ during solidification of a cast ingot. For powder metallurgy however it enables formation of a transient liquid phase during sintering which enhances the sintering process. Furthermore, $\mathrm{P}$ is a strong ferrite stabilizer and thus promotes the transport processes during sintering, the self-diffusion coefficient for Fe being about 2 orders of magnitude higher in ferrite than in austenite. Therefore addition of $\mathrm{P}$ enables sintering at least in part in the ferrite range even at the usual sintering temperatures of $1120 . .1250^{\circ} \mathrm{C}$ at which for plain iron, austenite is stable. In industrial practice, addition of $\mathrm{P}$ to alloy steels enables sintering in belt furnaces while attaining properties that otherwise would require a walking beam furnace, which means a considerable cost saving. The strengthening of the sintering contacts by the $\mathrm{P}$ effect results in higher strength without the usual loss of ductility $[12,13,25,26]$.

Also for phosphorus, however, embrittlement effects have been observed in sintered steels. These have in part been attributed to the formation of the transient liquid phase and the resulting $\mathrm{P}$ segregation as well as the deposition of oxygen residues from the $\mathrm{P}$ carrier at the grain boundaries. It has also been claimed that sintering in the ferrite + austenite range is preferable since it results in heterogeneous $\mathrm{P}$ distribution which is less prone to embrittlement that the plain ferritic state [27]. This is one of the reasons why the $\mathrm{P}$ 
content in sintered steels is rarely above 0.45 mass $\%$, at higher P levels embrittlement being significantly more probable.

Third elements may be useful, as e.g. C as austenite stabilizer; an appropriate combination of $\mathrm{P}$ and $\mathrm{C}$ can result in attractive sintering behaviour and mechanical properties [28]. On the other hand, addition of VIa elements such as $\mathrm{Cr}$ [29], Mo [30, 31], and $\mathrm{W}$ [31] have been shown to enhance embrittlement, esp. if the combination $\mathrm{Mo}+\mathrm{P}$ exceeds a certain limit. Introduction of Mo through the prealloying route is less critical that admixing.

\section{EXPERIMENTAL TECHNIQUES}

For Fe-P, iron samples with varying phosphorus content, namely $0 ; 0.15 ; 0.30$; $0.45 ; 0.6 ; 0.8$ and 1.0 mass percent, were prepared by the powder metallurgy route. Water atomised iron powder ASC 100.29 (Höganäs $\mathrm{AB}$ ) and fine $(40 \mu \mathrm{m})$ ferrophosphorus powder $\mathrm{Fe}_{3} \mathrm{P}$ (supplied by MIBA Sinter Austria $\mathrm{GmbH}$ ) were mixed as starting materials, and $0.5 \%$ microwax $\mathrm{C}$ (ethylene bisstearamide) was admixed as pressing lubricant. In part $0.5 \% \mathrm{C}$ were added as fine natural graphite (Kropfmühl UF4). Dry mixing was done for 60 min in a tumbling mixer.

Boron was introduced as ferroboron powder (Fe-21 mass\%B) supplied by IMR SAS Košice, once more in different contents. This powder was mostly fine but contained some coarse fraction that were not screened off but were retained as markers for liquid phase formation, coarse secondary pores indicating that liquid phase has been generated during sintering (see below). Once more, 0.5 mass\% EBS (Microwax C) was added as pressing lubricant and in one series carbon as natural graphite.

From all the mixes, standard impact test bars $55 \times 10 \times 10 \mathrm{~mm}$ (ISO 5754) were compacted at $600 \mathrm{MPa}$. The green samples were subsequently sintered in a pusher furnace at $1120^{\circ} \mathrm{C} / 1250^{\circ} \mathrm{C}$, respectively, for 60 minutes under a protecting atmosphere. For the $\mathrm{P}$ containing specimens this was flowing hydrogen; in a second series, performed with the composition $\mathrm{Fe}-0.8 \% \mathrm{P}$, the isothermal sintering time was varied between 5 and $60 \mathrm{~min}$. For the boron containing specimens, Ar was chosen as atmosphere to avoid the adverse interactions with either $\mathrm{N} 2$ or H2. The inhibition of densification by trapped Ar was regarded not too crucial here since full density was not a target.

Characterization of the specimens was done following standard techniques: The green density was determined from the mass and dimensions while the sintered density was measured through water displacement; here, the specimens were impregnated before measurement using a commercial waterstop spray, to avoid intrusion of water into open pores. Mechanical testing included Vickers hardness and Charpy impact energy on unnotched samples, since it has been found that hardness and impact energy are markedly better suited to describe the mechanical behaviour of sintered steels than the usual combination of $\mathrm{R}_{\mathrm{m}}$ and $\mathrm{A}$, in particular at low to moderate ductility levels. In all cases, metallographic investigations were performed, $2 \%$ Nital $\left(\mathrm{MeOH}-2 \% \mathrm{HNO}_{3}\right)$ being used as etchant. The fracture surfaces were investigated using an SEM Jeol 6400 in secondary electron mode. The boron distribution was studied in metallographic sections by secondary ion mass spectrometry (SIMS CAMECA 3f, primary ions $\mathrm{Cs}^{+}$at $15.5 \mathrm{keV}$ energy, $150 \mathrm{nA}$ current) [32]. 


\section{Phosphorus in sintered iron and steel}

\section{Plain Fe-P}

In Figure 1 the dimensional and mechanical properties of plain Fe-P prepared from water atomized iron powder and ferrophosphorus powder $\mathrm{Fe}_{3} \mathrm{P}$ are shown as a function of the phosphorus content. It is evident that while the green density steadily decreases with higher $\mathrm{P}$ content, the sintered density shows a pronounced increase between 0.30 and 0.60 mass $\% \mathrm{P}$, which agrees with the dimensional change shown in Fig.1b. This "jump" is more pronounced at the higher sintering temperature, which can be attributed to higher proportions of the transient liquid phase and thus faster $\mathrm{P}$ distribution, which in turn generates more ferrite (persistent liquid phase, which might also be an explanation, is not to be expected at the $\mathrm{P}$ levels present here, according to $[17,18]$.

However, this density increase is not mirrored in the impact energy: here almost the reverse occurs, i.e. those specimens that exhibit higher sintered density also show lower impact energy values. The hardness, in contrast, shows a consistent increase with higher $\mathrm{P}$ levels, indicating the strong solution hardening effect of $\mathrm{P}$ on ferrite. On the other hand, this also shows that the decrease of the impact energy is not a consequence of the hardness increase but can be attributed to a specific embrittling effect.
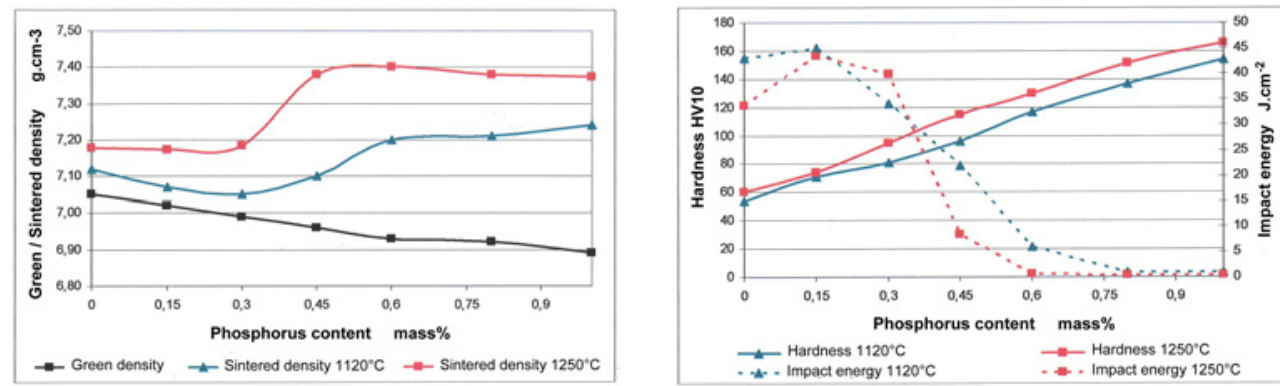

Fig.1. Properties of Fe-P as a function of the P-content. Compacted at $600 \mathrm{MPa}$, sintered 60 min at different temperatures in $\mathrm{H}_{2}$.

The fracture surfaces of the impact test bars are shown in Fig.2. Here it is clearly visible that at low $\mathrm{P}$ levels the typical fracture morphology of sintered plain iron is discernible, with ductile fracture of the sintering contacts indicated by dimples. With increasing $\mathrm{P}$ content, more and more intergranular fracture is observed, first locally visible and then spreading to larger areas. This once more confirms that the drop in impact energy is actually a consequence of intergranular embrittlement; in [33] it has been shown through AES analysis that it is actually phosphorus that causes the embrittlement there and not so much (or at least not only) oxygen as supposed to be the reason in [26]. Apparently a certain minimum $\mathrm{P}$ content is required to segregate to the grain boundaries, and spreading of locally enriched $\mathrm{P}$ also seems to be a role. Of course it should further be considered that the ferrite stabilizing effect of $\mathrm{P}$ also promotes grain growth (which is used to improve the magnetic properties, esp,. lower the coercive force, see [34]) and thus reduces the total grain boundary area, which means that the P present is concentrated on a smaller area and thus enriched more, which also enhances embrittlement.

When comparing the fracture surfaces of specimens sintered at 1120 and $1250^{\circ} \mathrm{C}$, respectively, it stands out clearly that also the temperature plays a major role: as also indicated by the impact energy data, more pronounced intergranular fracture is observed for 
the higher sintering temperature. While even for $\mathrm{Fe}-1.0 \% \mathrm{P}$ still some dimples are observed in the $1120^{\circ} \mathrm{C}$ sintered specimen, that sintering at $1250^{\circ} \mathrm{C}$ shows virtually $100 \%$ intergranular fracture. This indicates that $\mathrm{P}$ has been very evenly distributed at the grain boundaries; of course also the grain growth effect mentioned above plays a major role since not only higher $\mathrm{P}$ contents but also higher sintering temperatures promote grain growth.

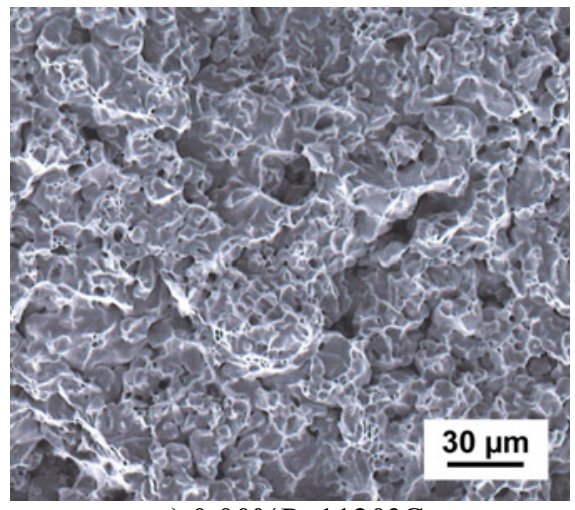

a) $0.00 \% \mathrm{P}, 1120^{\circ} \mathrm{C}$

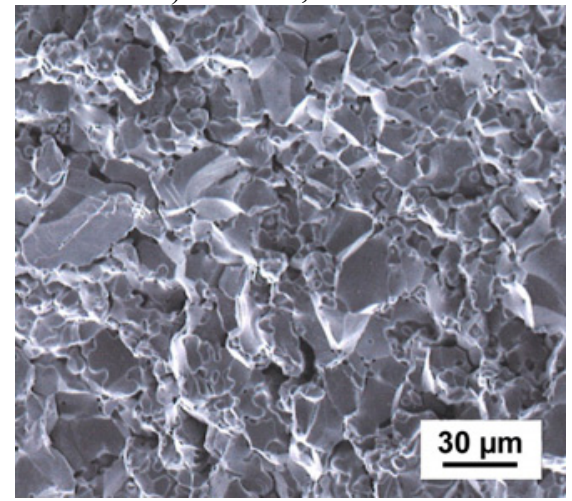

c) $0.60 \% \mathrm{P}, 1120^{\circ} \mathrm{C}$

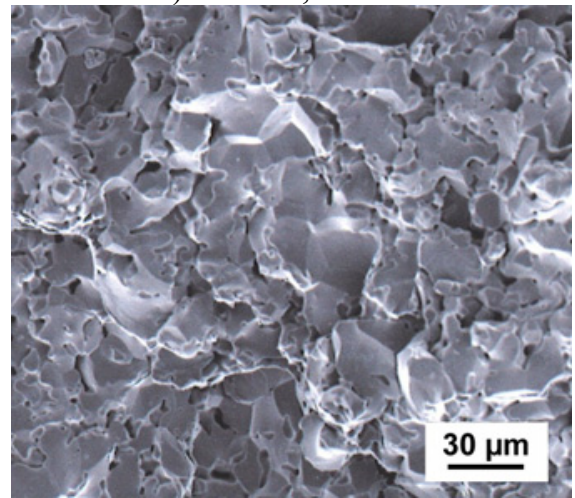

e) $0.30 \% \mathrm{P}, 1250^{\circ} \mathrm{C}$

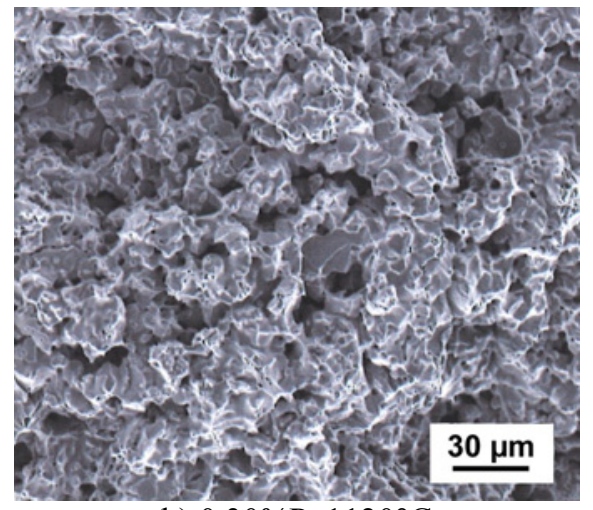

b) $0.30 \% \mathrm{P}, 1120^{\circ} \mathrm{C}$

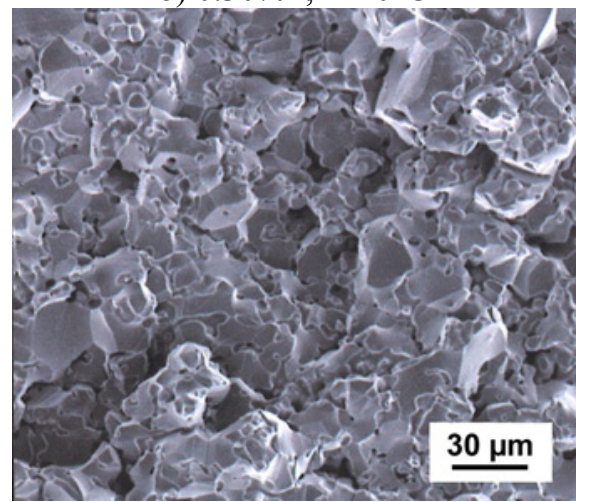

d) $1.00 \% \mathrm{P}, 1120^{\circ} \mathrm{C}$

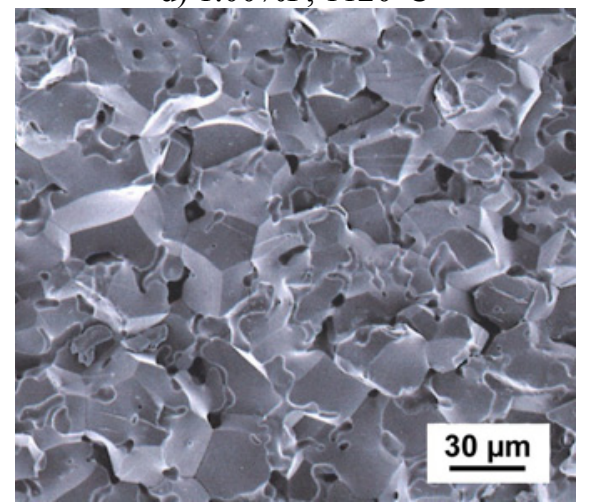

f) $0.60 \% \mathrm{P}, 1250^{\circ} \mathrm{C}$

Fig.2. Fracture surfaces of $\mathrm{Fe}-\mathrm{x} \% \mathrm{P}$, compacted at $600 \mathrm{MPa}$, sintered for $60 \mathrm{~min}$ at varying temperatures in $\mathrm{H}_{2}$. 
As stated above, there seems to be an effect of $\mathrm{P}$ spreading within the compact. This has been studied by varying the sintering time while the temperature has been held constant at $1120^{\circ} \mathrm{C}$. In Figure 3, fracture surfaces of specimens sintered for isothermal soaking periods between $5 \mathrm{~min}$ and $60 \mathrm{~min}$ are shown; the $\mathrm{P}$ content was chosen as $0.8 \%$ to show the grain boundary embrittlement as clearly as possible.

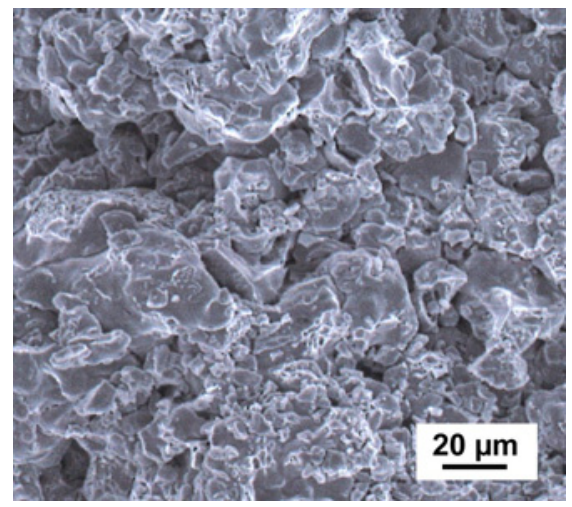

a) $5 \mathrm{~min}$

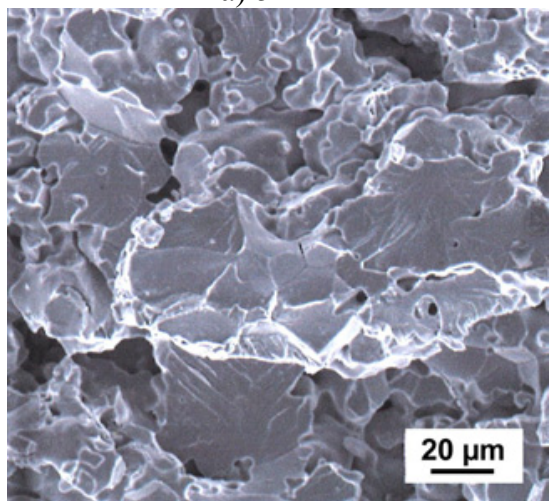

c) $15 \mathrm{~min}$

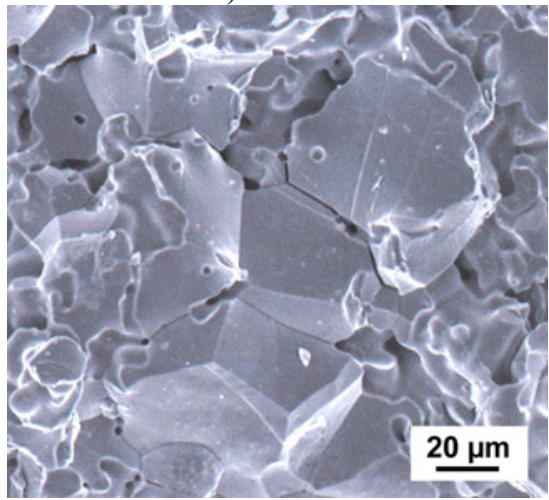

e) $40 \mathrm{~min}$

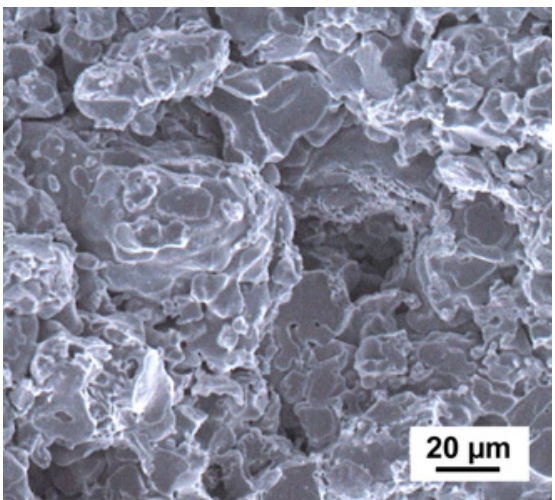

b) $10 \mathrm{~min}$

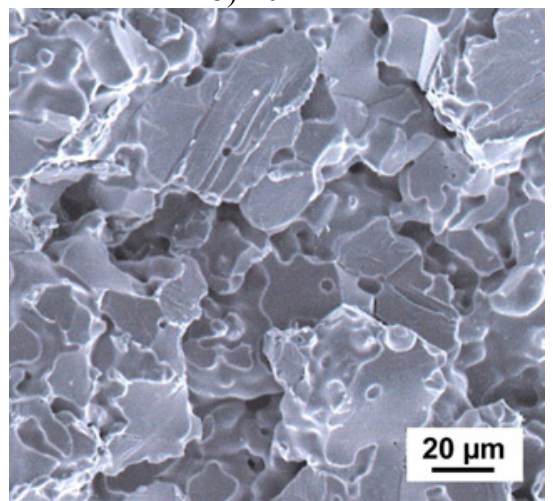

d) $20 \mathrm{~min}$

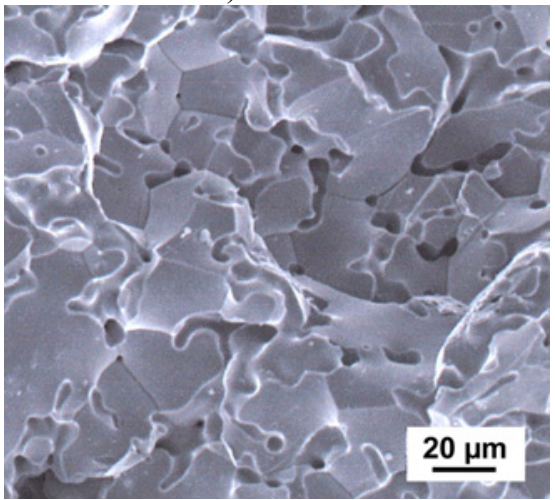

f) $60 \mathrm{~min}$

Fig.3. Impact fracture surfaces of $\mathrm{Fe}-0.8 \% \mathrm{P}$, sintered at $1120^{\circ} \mathrm{C}$ in $\mathrm{H}_{2}$ for different lengths of time. 
As can be seen from the fracture surfaces, there is initially ductile fracture of the sintering contacts, the size of which is however rather small (Fig.3a, b). With longer sintering times, some intergranular fracture becomes visible, but surprisingly in the intermediate stage also transgranular fracture occurs (Fig.3c), which can be attributed to the strengthening of the sintering contacts by alloying with $\mathrm{P}$, the fracture thus being shifted to the unalloyed particle core. If the sintering time is extended further, intergranular fracture dominates at the expense of both ductile and cleavage fracture, caused at least in part by the grain growth and resulting decrease of total grain boundary area, but also the effect of more homogeneous $\mathrm{P}$ distribution can be expected to contribute to the embrittlement effect.

The fact that this intergranular fracture occurs rather at longer sintering times also can be taken as an indicator that the explanation given in [26] that transient liquid phase is responsible for the embrittlement does not hold here since this liquid phase formation occurs in a very early stage of sintering; if it were a relevant mechanism, also after short time sintering intergranular embrittlement should occur. Of course it can be assumed that in the present case the heating rates were such that diffusion of PM into the Fe matrix was so fast that liquid phase was not formed any more, although the "push-in-push-out" sintering process done here should result in fairly rapid heating and thus favour formation of the Fe-P eutectic in an intermediate stage.

\section{Carbon-containing steels Fe-C-P}

It has been described in the literature that combination of phosphorus with carbon decreases the tendency to grain boundary embrittlement (e.g. [16]). This results in sintering in the ferrite-austenite range and thus in heterogeneous distribution of $\mathrm{P}$ and $\mathrm{C}$, the former being enriched in ferrite and the latter in austenite. Furthermore, the pronounced shrinkage observed with Fe-P at least at higher $\mathrm{P}$ contents and/or sintering temperatures, which is usually unfavourable for precision parts. can be significantly reduced.

In Figure 4, the properties of $\mathrm{Fe}-0.5 \% \mathrm{C}-\mathrm{x} \% \mathrm{P}$ are shown as a function of the $\mathrm{P}$ content. As can be clearly seen, the green density once more slightly drops with higher $\mathrm{P}$ contents, and also the sintered density in fact follows the same trend, i.e. there is not the pronounced densification observed with the C-free specimens between 0.30 and $0.60 \% \mathrm{C}$. Only at the highest $\mathrm{P}$ contents, from $0.8 \%$, densification is observed after sintering at $1250^{\circ} \mathrm{C}$, which can be taken as an indicator for formation of persistent liquid phase [29], as is the very pronounced grain coarsening observed (see Fig.5).

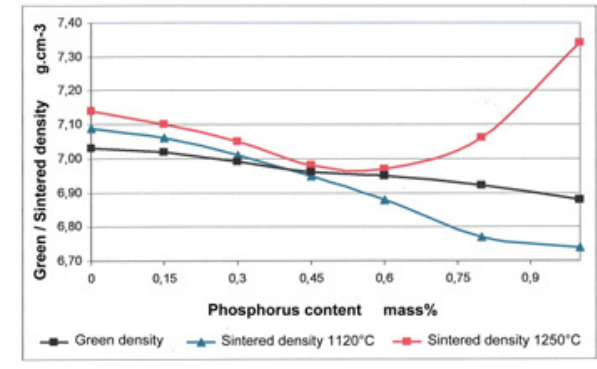

a) Green and sintered density

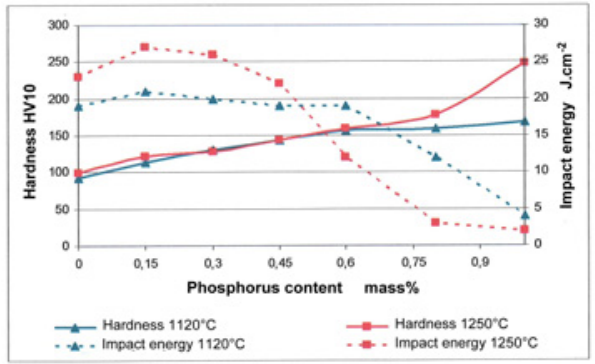

b) Hardness and impact energy

Fig.4. Dimensional and mechanical properties of $\mathrm{Fe}-0.5 \% \mathrm{C}-\mathrm{x} \% \mathrm{P}$ as a function of the phosphorus content. Compacted at $600 \mathrm{MPa}$, sintered 60 min in $\mathrm{N}_{2}$. 


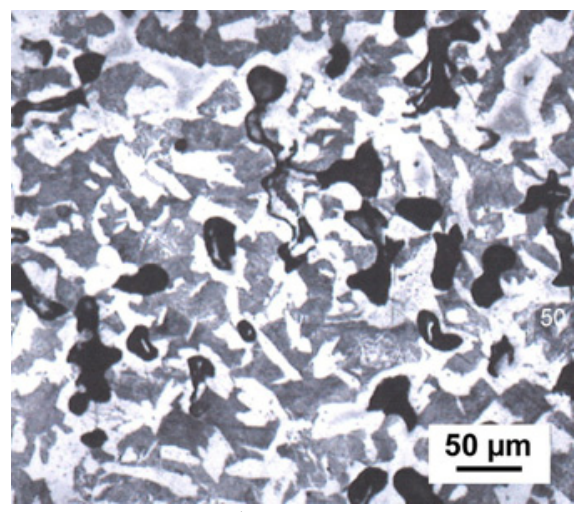

a) $1120^{\circ} \mathrm{C}$

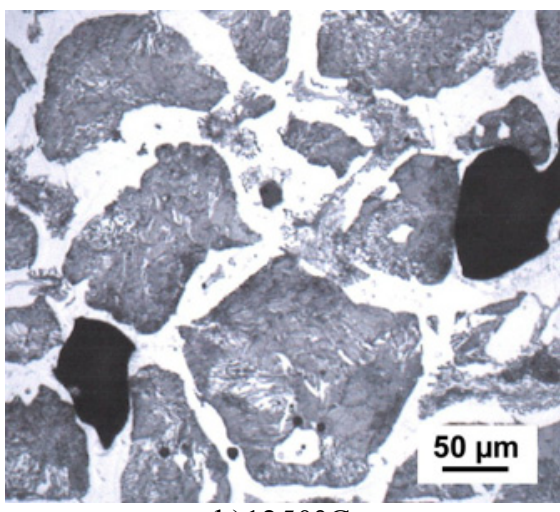

b) $12500^{\circ} \mathrm{C}$

Fig.5. Metallographic sections of Fe- $0.5 \% \mathrm{C}-1.0 \% \mathrm{P}$, compacted at $600 \mathrm{MPa}$, sintered 60 $\min$ in $\mathrm{N}_{2}$.

The mechanical properties show a similar trend as with Fe-P, though at different levels, for the hardness a steady increase with higher $\mathrm{P}$ content being recorded, with a more pronounced increase for $\mathrm{P}>0.8 \%$ and $1250^{\circ} \mathrm{C}$, which agrees with the trend of the density. Generally the hardness levels are higher for Fe-C-P than for Fe-P, as was to be expected. The graph of the impact energy is also similar in shape as for Fe-P, but is different insofar as the maximum values are lower - not surprising regarding the higher hardness - , and the drop towards lower values is less pronounced and occurs at higher P contents, which can be seen from Figures below which depict the Fe-P graphs against those for Fe-C-P (and for a $\mathrm{Cr}-\mathrm{Mo}$ prealloyed steel). This agrees with findings described in the literature that addition of carbon renders Fe-P less sensitive to embrittlement.

In Figure 6, impact fracture surfaces of Fe-C-P specimens are shown. Evidently the fracture surfaces of the low-P specimens differ not too much from the respective Fe-P specimens, dimple fracture dominating (Figs.6a, b). At higher $\mathrm{P}$ levels, transgranular cleavage fracture becomes increasingly visible, in particular in case of high sintering temperature (Fig.6f). When comparing Figs.6b and $\mathrm{d}$ and esp.6e and $\mathrm{f}$, the pronounced grain coarsening caused both by higher $\mathrm{P}$ contents and especially high sintering temperatures is evident.

Surprisingly, even the high-P specimens with very low impact energy, below 5

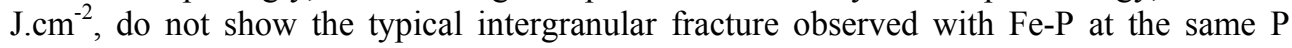
contents (which agrees with findings shown in [29]). This indicates that in this case it is not the grain boundary that is the weakest link, but in contrast the sintering necks - and the grain boundaries contained - seem to be rather strong, crack propagation therefore being shifted to the particle cores which fail through cleavage. The observed macroscopic embrittlement thus seems to be caused by the combined hardening effects of carbon, which forms a pearlitic structure, and of phosphorus, which considerably hardens the ferrite lattice (see [3], p.202). Another contribution surely comes from the coarser microstructure which, as visible from Fig.4, contains larger pearlite areas which offer cleavage planes that favour low-energy crack propagation there. This can also be identified as one of the reasons why high temperature sintering in this case results in lower impact energy values, which is rather uncommon otherwise. 


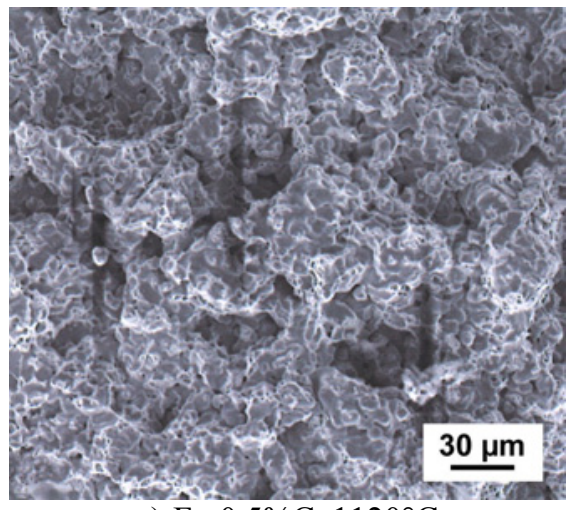

a) $\mathrm{Fe}-0.5 \% \mathrm{C}, 1120^{\circ} \mathrm{C}$

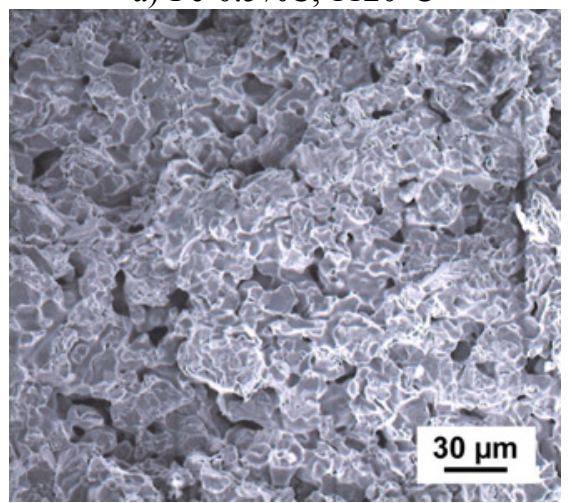

c) $\mathrm{Fe}-0.5 \% \mathrm{C}-0.6 \% \mathrm{P}, 1120^{\circ} \mathrm{C}$

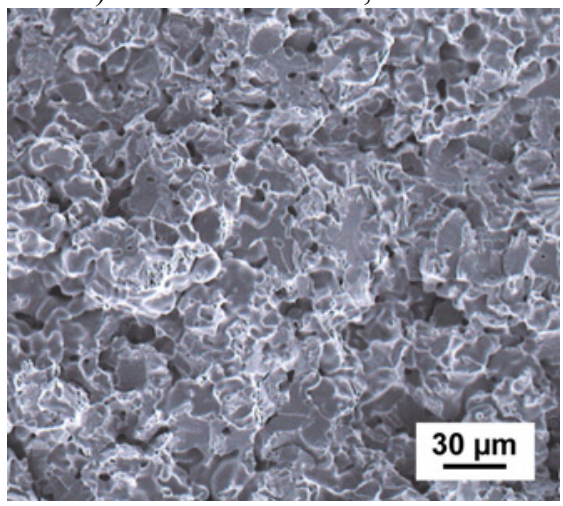

e) $\mathrm{Fe}-0.5 \% \mathrm{C}-0.3 \% \mathrm{P}, 1250^{\circ} \mathrm{C}$

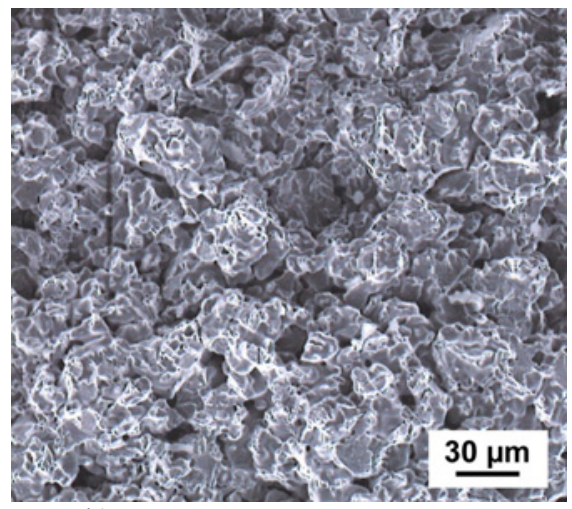

b) $\mathrm{Fe}-0.5 \% \mathrm{C}-0.3 \% \mathrm{P}, 1120^{\circ} \mathrm{C}$

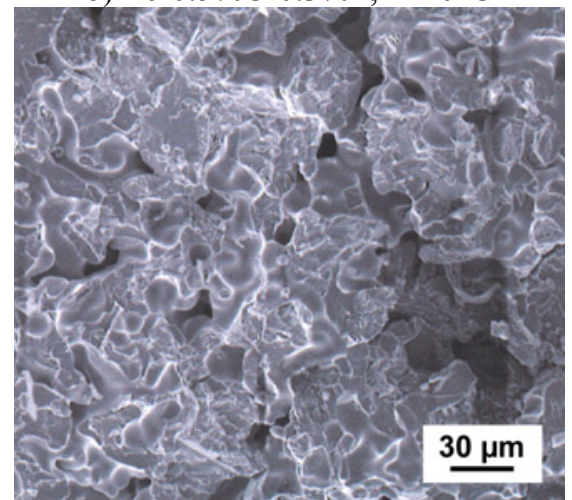

d) $\mathrm{Fe}-0.5 \% \mathrm{C}-1.0 \% \mathrm{P}, 1120^{\circ} \mathrm{C}$

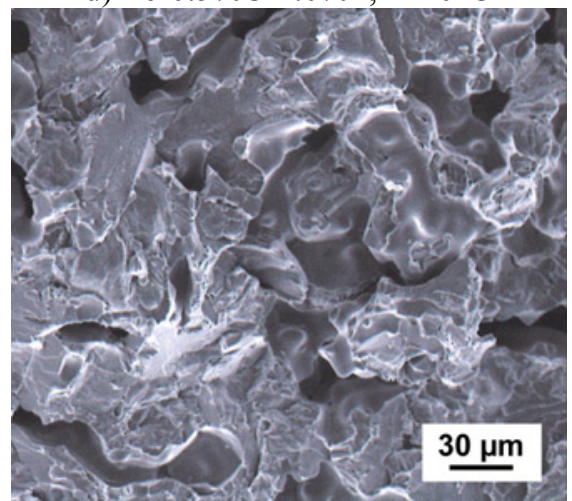

f) $\mathrm{Fe}-0.5 \% \mathrm{C}-1.0 \% \mathrm{P}, 1250^{\circ} \mathrm{C}$

Fig.6. Impact fracture surfaces of $\mathrm{Fe}-0.5 \% \mathrm{C}-\mathrm{x} \% \mathrm{P}$, compacted at $600 \mathrm{MPa}$, sintered $60 \mathrm{~min}$ in $\mathrm{N}_{2}$.

\section{Cr-Mo prealloyed steels $\mathrm{Fe}-\mathrm{Cr}$-Mo-C-P}

In previous studies it has been shown that combination of VIa elements, especially Mo, and $\mathrm{P}$ can result in pronounced embrittlement [30.31], which is more severe for steels from powder mixes than for prealloyed grades. Similar effects have been shown for Cr-Mo prealloy steels, esp. at higher Cr contents [29]. In this latter case it had been shown that in 
the sintered state, cleavage fracture dominated while after sinter hardening, intergranular fracture was observed. This can be interpreted such that apparently the probability of transgranular cleavage determines the fracture mode: if the microstructure is relatively coarse and exhibits preferred fracture planes within the original powder particles, cleavage occurs while with sinter hardened (or probably also quenched and tempered) materials which show finer microstructure, weakening of the grain boundaries becomes effective, and the specimens fail there.

In order to check the effect of metallic alloy elements that change the transformation behaviour of steels during cooling, compacts were prepared from a $\mathrm{Cr}-\mathrm{Mo}$ prealloyed steel powder, processing being done in the same way as for Fe-C-P, i.e. sintering in N2. The dimensional and mechanical properties are shown as a function of the $\mathrm{P}$ content in Fig.7; in Fig.8 the impact energy graphs are shown for the various materials studied.

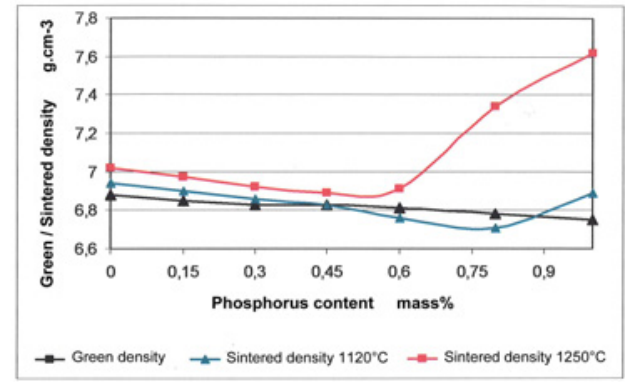

a)Green and sintered density

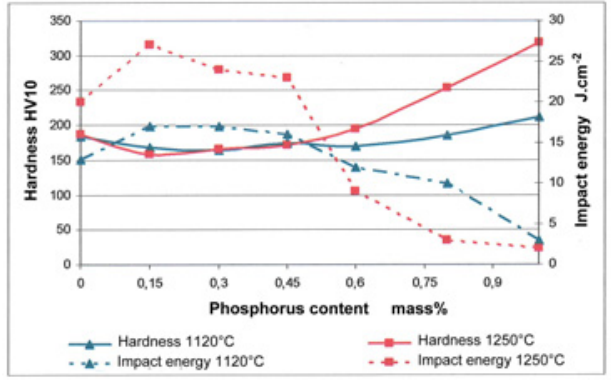

b) Hardness and impact energy

Fig.7. Dimensional and mechanical properties of (Fe-1.5\%Cr- $0.2 \% \mathrm{Mo})-0.5 \% \mathrm{C}-\mathrm{x} \% \mathrm{P}$ as a function of the phosphorus content. Compacted at $600 \mathrm{MPa}$, sintered $60 \mathrm{~min}$ in $\mathrm{N}_{2}$.

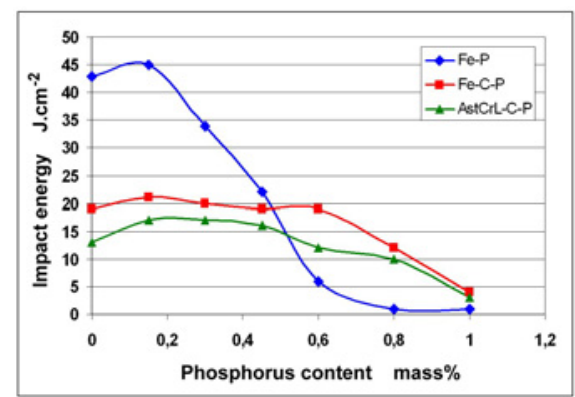

a) $1120^{\circ} \mathrm{C}$

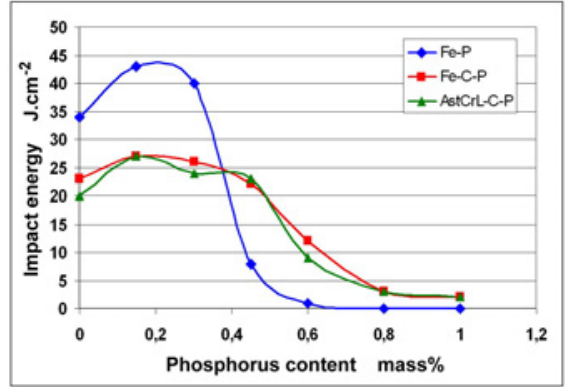

b) $1250^{\circ} \mathrm{C}$

Fig.8. Impact energy of $\mathrm{Fe}-\mathrm{x} \% \mathrm{P}, \mathrm{Fe}-0.5 \% \mathrm{C}-\mathrm{x} \% \mathrm{P}$ and $(\mathrm{Fe}-1.5 \% \mathrm{Cr}-0.2 \% \mathrm{Mo})-0.5 \% \mathrm{C}-\mathrm{x} \% \mathrm{P}$ as a function of the $\mathrm{P}$ content. Compacted at $600 \mathrm{MPa}$, sintered for $60 \mathrm{~min}$ in $\mathrm{H}_{2}(\mathrm{Fe}-\mathrm{P})$ or $\mathrm{N}_{2}$ (Fe-C-P, Cr-Mo prealloy).

As can be seen from Figure $7 \mathrm{a}$, the dimensional behaviour of the $\mathrm{Cr}$ prealloyed steel is very similar to that of Fe-C-P; also here, the sintered density is similar to the green density for both sintering temperatures, but only up to about $0.6 \% \mathrm{P}$, then the density increases significantly, but only for the higher sintering temperature, which indicates formation of persistent liquid phase.

For the hardness, there is a slight drop at 0.15 to $0.30 \% \mathrm{P}$ compared to the $\mathrm{P}$-free material. This is at first surprising but can be explained when studying the microstructures 
formed: while the carbon-free material shows a fine bainitic microstructure, the $\mathrm{P}$ containing variants are pearlitic-ferritic (Fig.9): as a consequence of the ferrite-stabilizing effect of $\mathrm{P}$, the transformation occurs at higher temperatures, in the pearlite range, and the fairly soft ferrite results in slightly lower hardness. At higher P levels the solid solution strengthening effect of $\mathrm{P}$ becomes more pronounced, and HV increases; at high P levels and sintering temperature, the densification results in up to $300 \mathrm{HV}$.

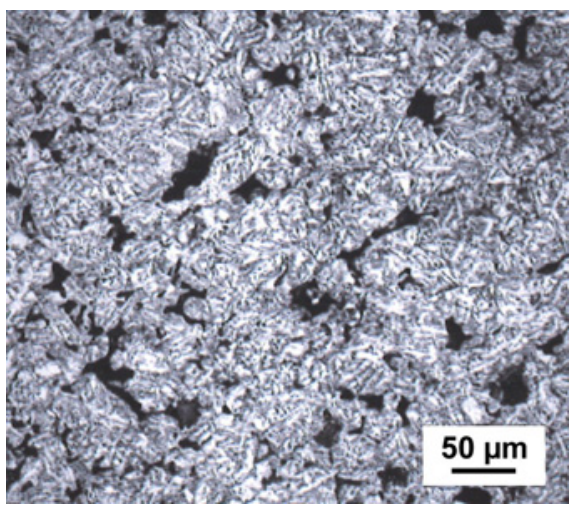

a) $(\mathrm{Fe}-1.5 \% \mathrm{Cr}-0.2 \% \mathrm{Mo})-0.5 \% \mathrm{C}$

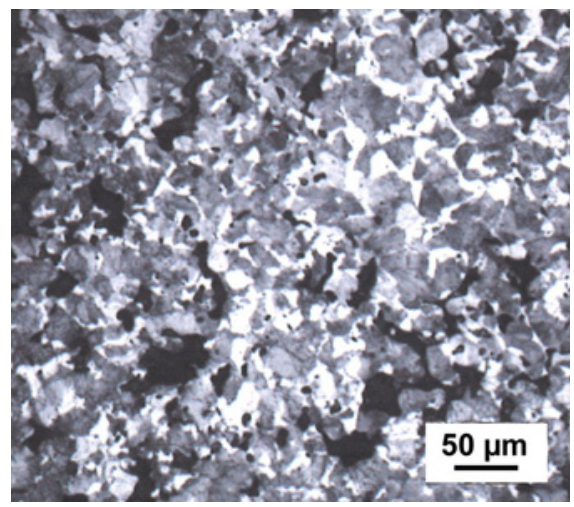

b) $(\mathrm{Fe}-1.5 \% \mathrm{Cr}-0.2 \% \mathrm{Mo})-0.5 \% \mathrm{C}-0.3 \% \mathrm{P}$

Fig.9. Microstructures of (Fe-1.5\%Cr-0.2\%Mo)- $0.5 \% \mathrm{C}-\mathrm{x} \% \mathrm{P}$. Compacted at $600 \mathrm{MPa}$, sintered $60 \mathrm{~min}$ at $1120 \mathrm{C}$ in $\mathrm{N}_{2}$.

For the impact energy, virtually the same trend as with Fe-C-P is observed, as can be clearly seen from Figs.8a, b: also here, the material is markedly more tolerant towards $\mathrm{P}$ addition than is plain $\mathrm{Fe}$. At $1120^{\circ} \mathrm{C}$ sintering temperature, the impact energy values are slightly below those recorded for Fe-C-P while at $1250^{\circ} \mathrm{C}$ almost identical data are recorded. This shows that at least for the alloy element contents and sintering conditions, the tendency for embrittlement is not enhanced by the addition of $\mathrm{Cr}$ (and some Mo).

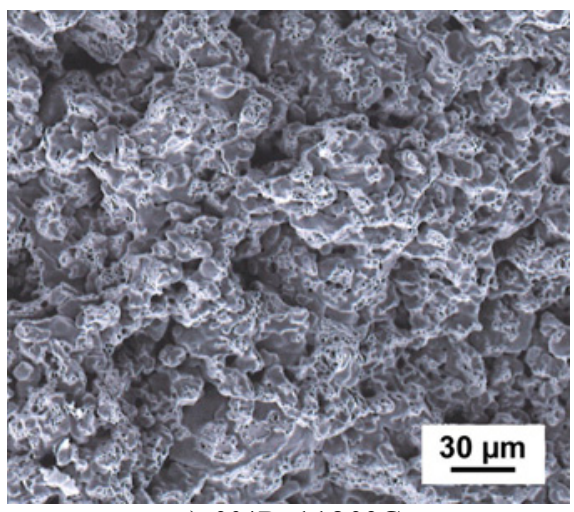

a) $0 \% \mathrm{P}, 1120^{\circ} \mathrm{C}$

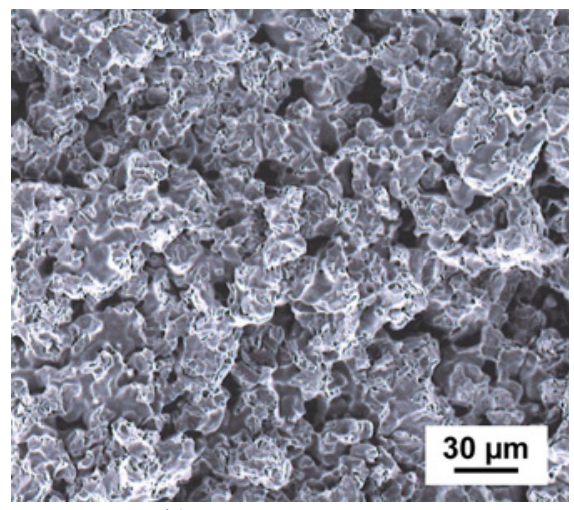

b) $0.6 \% \mathrm{P}, 1120^{\circ} \mathrm{C}$ 


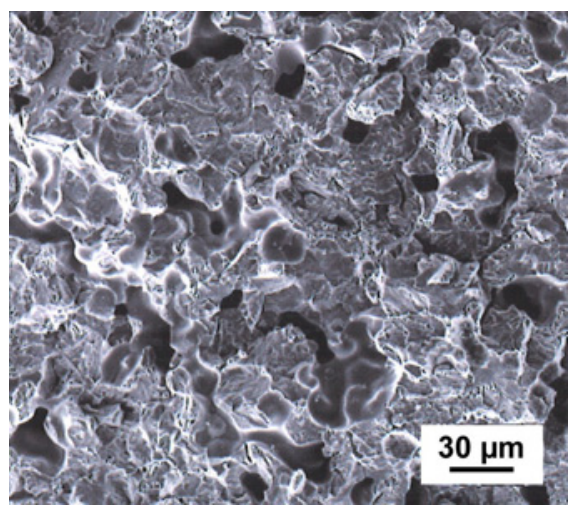

c) $1.0 \% \mathrm{P}, 1120^{\circ} \mathrm{C}$

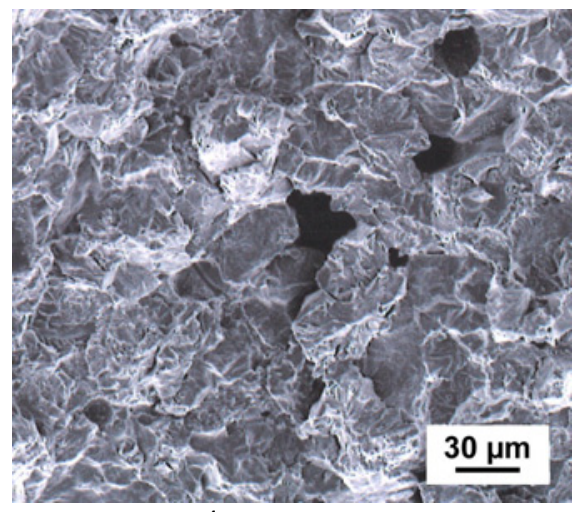

d) $1.0 \% \mathrm{P}, 1250^{\circ} \mathrm{C}$

Fig.10. Impact fracture surfaces of (Fe-1.5\%Cr- $0.2 \% \mathrm{Mo})-0.5 \% \mathrm{C}-\mathrm{x} \% \mathrm{P}$. Compacted at 600 $\mathrm{MPa}$, sintered 60 min in $\mathrm{N}_{2}$.

This is confirmed by the fracture surfaces (Fig.10): also here, ductile fracture with dimples dominates at low $\mathrm{P}$ contents, but even at very high $\mathrm{P}$ contents and after sintering at high temperatures, in which case pronounced microstructural coarsening is observed and very low impact energy values are recorded, transgranular cleavage occurs but not the typical intergranular failure usually attributed to embrittlement caused by phosphorus. Therefore it can be concluded that interaction of $\mathrm{P}$ with $\mathrm{Cr}$ in prealloyed form is at least not sufficiently effective to cause intergranular embrittlement unless the.matrix is strengthened by heat treatment, in which case the grain boundaries become the weakest link (see [29]).

\section{Boron in sintered iron and steel}

\section{Binary iron-boron systems}

In a first test run, plain binary Fe-B specimens were investigated, the boron content being varies $0.0 \ldots 0.6$ mass $\%$. Sintering was done in Ar which is an inert atmosphere towards B; the lower densification cause by Ar trapping was taken into account. In Fig.11 the properties obtained are shown. Evidently the green density slightly drops with increasing B content - due to the adverse effect of the admixed hard ferroboron on the compressibility - while on the other hand the sintered density increases significantly. Sintering at $1300^{\circ} \mathrm{C}$ is more effective than at $1200^{\circ} \mathrm{C}$, as a consequence of the higher amount of liquid phase present during sintering. As can be seen from the graphs the density increases up to about 0.15 to $0.20 \%$ and then levels off, in particular when sintering at $1300^{\circ} \mathrm{C}$, which effect can be attributed to trapping of the argon in the pores, Ar being completely insoluble in iron even at high temperatures. Therefore, closed pores filled with Ar remain stable during sintering, pore shrinkage causing increase of the internal Ar pressure. Because of this "argon trapping" effect, materials to be sintered to full density heavy alloys, hardmetals, tool steels - are never sintered in argon [35,36].

The hardness increases consistently with increasing B content while for the impact energy typical "windows" of optimum B content are discernible. The window is slightly narrower for $1300^{\circ} \mathrm{C}$ sintering temperature than for $1200^{\circ} \mathrm{C}$, indicating that at $1300^{\circ} \mathrm{C}$ the critical liquid phase content - that results in continuous boride networks after sintering - is obtained at lower B contents than at $1200^{\circ} \mathrm{C}$. Nevertheless, the impact energy values obtained are quite impressive $->100{\mathrm{~J} . \mathrm{cm}^{-2}}^{-}$for $0.10 \%$ and $0.15 \% \mathrm{~B}$ when sintering at 
$1300^{\circ} \mathrm{C}$ - which indicates that here the desired sintering effect has really been obtained without embrittlement. This agrees with results decribed in [37] that without C, also alloyed steels tolerate fairly high B levels without drop of strength.

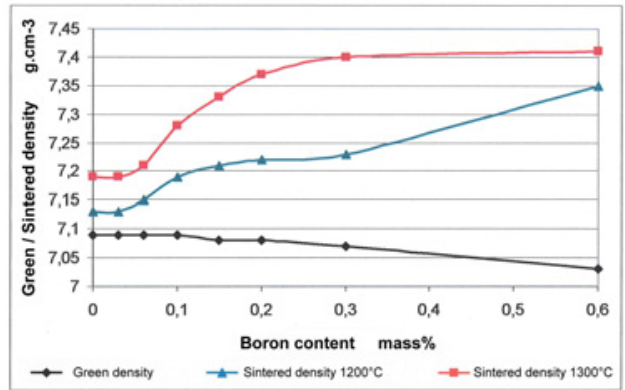

a) Density of $\mathrm{Fe}-\mathrm{X} \% \mathrm{~B}$

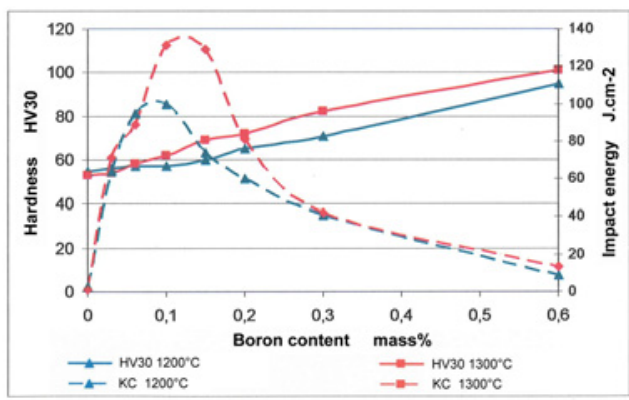

b) Hardness and impact energy

Fig.11. Properties of Fe-x\%B sintered in Ar 99.999 as a function of the B content. FeB21, compacted at $600 \mathrm{MPa}$, sintered $60 \mathrm{~min}$ isothermal.

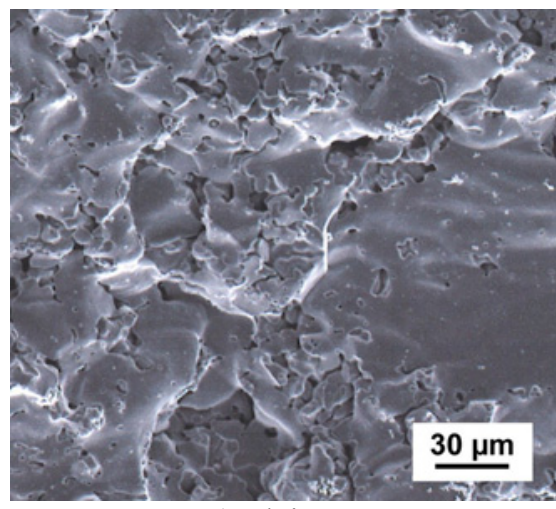

a) Plain Fe

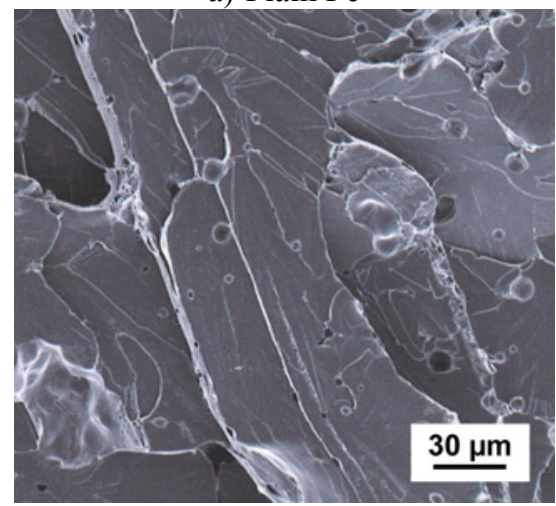

c) $\mathrm{Fe}-0.15 \% \mathrm{~B}$

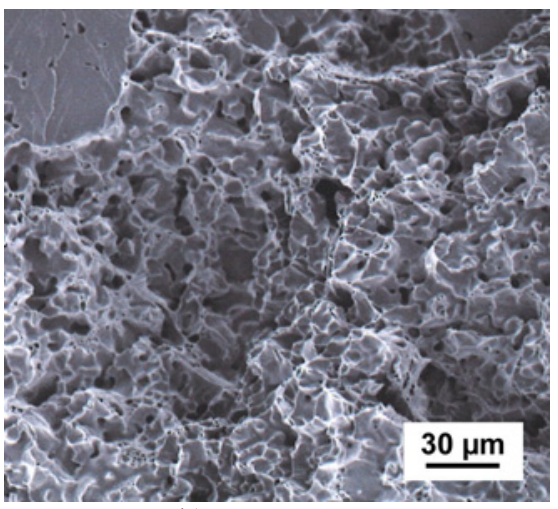

b) $\mathrm{Fe}-0.06 \% \mathrm{~B}$

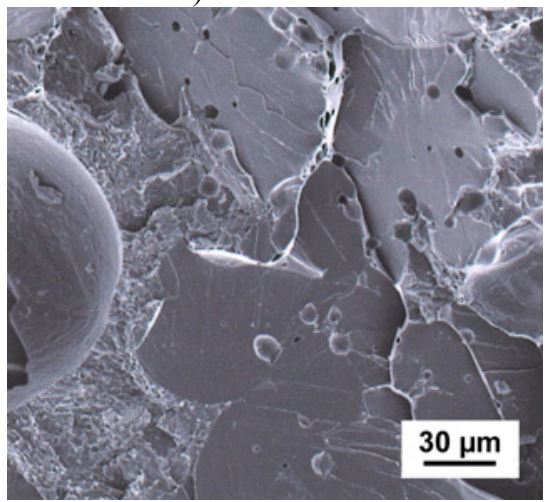

d) $\mathrm{Fe}-0.30 \% \mathrm{~B}$

Fig.12. Fracture surfaces of Fe- $\mathrm{x} \% \mathrm{~B}$, sintered $60 \mathrm{~min}$ at $1300^{\circ} \mathrm{C}$ in Ar. Ferroboron Fe-21B.

The low impact energy values obtained for the plain iron reference materials can be attributed to the excessive grain growth observed with high purity plain iron during the 
austenite-ferrite transformation [38, 39]. Such very coarse-grained specimens are sensitive to intergranular fracture with very low impact energy [38-40]. This is also clearly evident from the fracture surfaces shown in Fig.12: Figure 12a depicts the plain iron specimen which shows intergranular decohesion of the very large grains. This coarsening effect disappears if further elements are added such as $\mathrm{C}, \mathrm{N}$ or, in the present case, $<0.1 \% \mathrm{~B}$ (Fig.12b), and ductile rupture dominates, with occasional cleavage. At higher B levels, cleavage is the main failure mode, but surprisingly this emerges both for the reasonably ductile Fe- $0.15 \% \mathrm{~B}$ and the brittle Fe- $0.30 \% \mathrm{~B}$ (Figs. 12c, d). This once more confirms that transgranular cleavage does not necessarily mean macroscopically brittle fracture since considerable plastic deformation may have occurred before fracture. Tungsten heavy alloys are a clear example for this behaviour.

On the other hand, low-carbon sintered iron and steels typically fail through ductile rupture; this is not observed here which indicates that, as described above for Fe- $\mathrm{P}(-$ $\mathrm{X})$, the sintering contacts are no more the weak areas; rather the large ferrite planes generated through grain coarsening tend to promote cleavage fracture. Here once more it is evident that pores are highly effective grain growth inhibitors; as soon as densification has proceeded to a certain level, the grains grow to a size as typical for wrought steels at the same temperature [41].

\section{Ternary Iron-carbon-boron}

For Fe-P systems it has been shown that the material is markedly less sensitive to embrittlement in presence of carbon (see also [28]). Therefore, experiments were carried out also with $\mathrm{Fe}-\mathrm{B}, 0.8 \% \mathrm{C}$ being admixed to show the effect of carbon most clearly. Sintering was done in Ar, as the most inert atmosphere after vacuum. The properties obtained are shown in Fig.13.

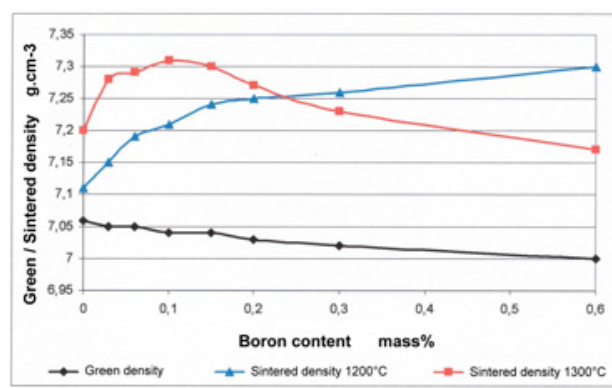

a) Density of $\mathrm{Fe}-0.8 \% \mathrm{C}-\mathrm{x} \% \mathrm{~B}$

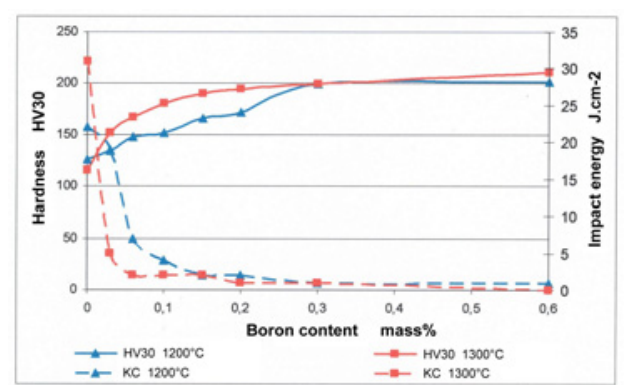

b) Hardness and impact energy

Fig.13. Properties of Fe- $0.8 \% \mathrm{C}-\mathrm{x} \% \mathrm{~B}$ sintered in $\mathrm{Ar}$ as a function of the $\mathrm{B}$ content. FeB21, compacted at $600 \mathrm{MPa}$, sintered $60 \mathrm{~min}$ isothermal.

It is evident that the trends observed are similar in principle to those obtained with plain Fe-B. However, in contrast to Fe-P-C esp. the impact graphs are shifted to lower B contents, which means that the materials are more sensitive to embrittlement if carbon is added. In fact, the highest impact energy values are observed with the boron-free reference material, and even boron levels $<0.05 \%$ result in pronounced drop of the impact energy, more so after sintering at the higher temperature. This indicates that also here the coarsening of the microstructure might be one of the reasons for the poor impact behaviour. Generally, the activating effect of B addition seems to be less controllable in presence of carbon. On the other hand it should be considered that here a fairly high $\mathrm{C}$ content was 
chosen. As shown e.g. by Selecka et al [37, 42], at lower carbon levels sintered steels can tolerate more boron without embrittlement. It seems therefore that a careful balance between the interstitial elements $\mathrm{B}$ and $\mathrm{C}$ is required to benefit from sinter activation without sacrificing mechanical properties.

The fracture surfaces (Fig.14) confirm that boron activation on one hard strengthens the sintering contacts: while for plain $\mathrm{Fe}-\mathrm{C}$ ductile rupture of individual sintering necks is the typical failure mode, even at low B levels $(0.06 \%)$ cleavage is the only failure mode, and also the massive grain growth is clearly discernible. On the other hand, this cleavage occurs without significant energy absorption, as clearly indicated by the low impact energy values. Intergranular failure, which would be expected at the presence of brittle boride networks, is not observed. Therefore the hypothesis that continuous boride networks are exclusively responsible for the brittle behaviour of $\mathrm{Fe}-\mathrm{B}$ and $\mathrm{Fe}-\mathrm{B}-\mathrm{C}$ should be critically checked.

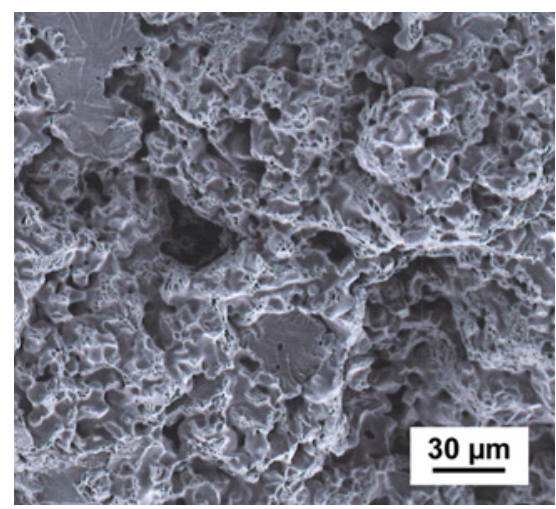

a) $\mathrm{Fe}-0.8 \% \mathrm{C}$

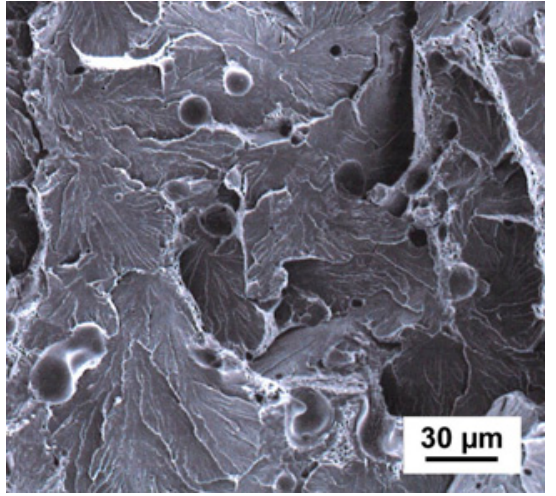

b) $\mathrm{Fe}-0.8 \% \mathrm{C}-0.06 \% \mathrm{~B}$

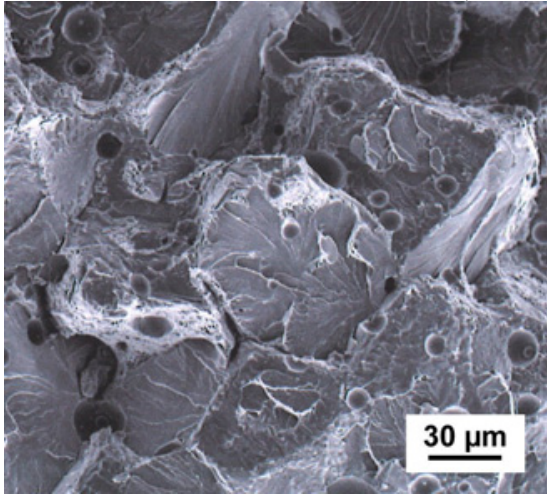

c) $\mathrm{Fe}-0.8 \% \mathrm{C}-0.3 \% \mathrm{~B}$

Fig.14. Fracture surfaces of $\mathrm{Fe}-0.8 \% \mathrm{C}-\mathrm{x} \% \mathrm{~B}$ sintered at $1300^{\circ} \mathrm{C}$ in $\mathrm{Ar}$.

\section{CONCLUSION}

The mechanical behaviour of iron and carbon steels containing phosphorus and boron, respectively, has been studied. It could be shown that $\mathrm{P}$ is more tolerant regarding mechanical response than boron, although the response is significantly affected by further elements. In the binary systems Fe-P and Fe-B, the threshold for embrittlement is around 
0.3 .. 0.45 mass $\%$ for $\mathrm{P}$ and about 0.2 mass $\%$ for $\mathrm{B}$. If taken not as mass $\%$ but as atomic $\%$, the threshold is even higher for $\mathrm{B}$, at about 1.03 at $\%$ compared to 0.81 at $\%$ for $\mathrm{P}$. This however changes dramatically if carbon is added: here, the tendency of $\mathrm{P}$ to cause embrittlement is markedly lowered, the threshold $\mathrm{P}$ content increasing to 0.45 ..0.6 mass $\%$ in $\mathrm{Fe}-0.5 \% \mathrm{C}$-P while for boron even $0.05 \%$ dramatically lower the impact energy of $\mathrm{Fe}$ $0.8 \% \mathrm{C}-\mathrm{B}$. In both cases, however, transgranular cleavage dominates, indicating that not so much weak grain boundary areas - segregation in case of $\mathrm{P}$ and solidified eutectic for $\mathrm{B}$ are responsible but apparently low energy cleavage right through the matrix grain cores.

\section{Acknowledgement}

This work was financially supported by the Austrian Fonds zur Förderung der wissenschaft-lichen Forschung (FWF project no.14889). Furthermore, the assistance and advice of A.Šalak, M.Selecká and E.Dudrová, IMR Kosice, are gratefully acknowledged, as is the support by R. de Oro Calderon, Vienna, with thermodynamic calculations.

\section{REFERENCES}

[1] Haynes, R.: The mechanical properties of sintered metals. London : Freund Publishers, 1981

[2] Bocchini, GF.: Int. J. Powder Metall., vol. 22, 1986, p. 185

[3] Šalak, A.: Ferrous Powder Metallurgy. Cambridge : Cambridge Int. Sci. Publ., 1995

[4] Danninger, H.: Pract. Metallogr., vol. 31, 1994, no. 2, p. 57

[5] Danninger, H., Zengin, OZ., Drozda, M.: Metal Powder Report, vol. 41, 1986, p. 833

[6] Höganäs Handbook. Vol.4: Warm Compaction. Höganäs : Höganäs AB, 1998

[7] Skoglund, P.: Powder Metall., vol. 44, 2001, no. 3, p. 199

[8] Sandner, C., Dickinger, J., Rößler, H., Orth, P. In: Proc. PM2004 World Congress, Vienna. Eds. H. Danninger, R. Ratzi. Vol. 5. Shrewsbury : EPMA, 2004, p. 657

[9] Danninger, H.: Powder Metall. Int., vol. 24, 1992, no. 2, p. 73

[10] Whittaker, D.: Powder Metallurgy Review, vol. 4, 2015, no. 2, p. 35

[11] Dautzenberg, N., Dorweiler, HJ.: Powder Metall. Int., vol. 17, 1985, no. 6, p. 279

[12] Lenel, FV.: U.S.Pat. 2226520, 1940

[13] Eisenkolb, F.: Arch. Eisenhüttenwesen, vol. 24, 1953, p. 257

[14] Benesovsky, F., Hotop, W., Frehn, F.: Planseeber. Pulvermet., vol. 3, 1955, p. 57

[15] German, RM., Rabin: Powder Metall., vol. 28, 1985, no. 1, p. 7

[16] Molinari, A., Straffelini, G., Pieczonka, T., Kazior, J.: Int. J. Powder Metall., vol. 34, 1998, no. 2, p. 21

[17] ASM Handbook. Vol.3: Alloy Phase Diagrams. Materials Park OH : ASM

[18] Raghavan, VG.: Phase diagrams of ternary iron alloys. Part 3: Ternary systems containing iron and phosphorus. Calcutta : Indian Int. of Metals, 1988

[19] Huppmann, WJ., Petzow, G.: Z. Metallkunde, vol. 67, 1976, p. 579

[20] German, RM.: Liquid phase sintering. New York : Plenum, 1985

[21] Kang, SJL.: Sintering - Densification, grain growth and microstructure. Oxford : Elsevier - Butterworth-Heinemann, 2005

[22] Danninger, H., Jangg, G., Giahi, M.: Mat.-Wiss. u. Werkstofftech., vol. 19, 1988, p. 205

[23] Vassileva, V., Danninger, H., Strobl, S., Gierl, C. In: Proc. EuroPM2007 Toulouse. Vol. 1. Shrewsbury : EPMA, 2007, p. 53

[24] Selecká, M., Bureš, R. In: Proc. Conf. Metallography 1998. Kosice : IMR, 1998, p. 122

[25] Lindskog, P., Carlsson: Powder Metall. Int., vol. 4, 1972, no. 1, p. 39

[26] Lindskog, P.: Powder Metall., vol. 16, 1973, p. 374 
[27] Engdahl, P.: Modern Dev. in Powder Metall., vol. 20, 1988, p. 655

[28] Molinari, A., Straffelini, G., Fontanari, V., Canteri, R.: Powder Metall., vol. 35, 1992, no. 4 , p. 285

[29] Danninger, H., Gierl-Mayer, C., Jaliliziyaeian, M.: Powder Metall. Progress, vol. 14, 2014, no. 1, p. 11

[30] Danninger, H., Üregen, B.: Powder Metall. Progress, vol. 16, 2016, no. 1, p. 14

[31] Üregen, B.: Diploma thesis. TU Wien, 1993

[32] Krecar, D., Vassileva, V., Danninger, H., Hutter, H.: Anal. Bioanal. Chem., vol. 379, 2004, p. 610

[33] Vassileva, V., Krecar, D., Tomastik, C., Gierl-Mayer, C., Hutter, H., Danninger, H.: Powder Metall. Progress, vol. 15, 2015 no. 1, p. 36

[34] Jangg, G., Drozda, M., Danninger, H., Eder, G.: Powder metall. Int., vol. 16, 1984, no. 6 , p. 264

[35] German, RM., Churn, KS.: Metall. Trans., vol. 15A, 1984, p. 747

[36] Cho, SJ., Kang, SJL., Yoon, DN.: Metall. Trans., vol. 17A, 1986, p. 2175

[37] Selecká, M., Salak, A., Danninger, H.: J.Mater.Processing Technol., vol. 143-144, 2003, p. 910

[38] Lehr, P.: C.R.Acad.Sci.France, vol. 242, 1956, p. 1172

[39] Danninger, H.: Powder Metall. Progress, vol. 3, 2003, p. 75

[40] Kuroki, H., Suzuki, HY.: Mater. Transactions, vol. 47, 2006, p. 2449

[41] Dlapka, M., Strobl, S., Danninger, H., Gierl, C.: Pract. Metallogr., vol. 47, 2010, no. 12, p. 686

[42] Selecká, M., Šalak, A., Danninger, H., Parilak, L. In: Proc. 2000Powder Metallurgy World Congress, Kyoto. Part 1. Tokyo : JPMA, 2000, p. 16 